University of Nebraska - Lincoln

DigitalCommons@University of Nebraska - Lincoln

1991

\title{
The Use of Health Service Areas for Measuring Provider Availability
}

Diane M. Makuc

National Center for Health Statistics

Bengt Haglund

The National Board of Health and Welfare, bengt.haglund@sos.se

Deborah D. Ingram

Centers for Disease Control and Prevention, popest@cdc.gov

Joel C. Kleinman

National Center for Health Statistics

Jacob J. Feldman

National Center for Health Statistics

Follow this and additional works at: https://digitalcommons.unl.edu/publichealthresources

Part of the Public Health Commons

Makuc, Diane M.; Haglund, Bengt; Ingram, Deborah D.; Kleinman, Joel C.; and Feldman, Jacob J., "The Use of Health Service Areas for Measuring Provider Availability" (1991). Public Health Resources. 262.

https://digitalcommons.unl.edu/publichealthresources/262

This Article is brought to you for free and open access by the Public Health Resources at DigitalCommons@University of Nebraska - Lincoln. It has been accepted for inclusion in Public Health Resources by an authorized administrator of DigitalCommons@University of Nebraska - Lincoln. 


\title{
The Use of Health Service Areas for Measuring Provider Availability*
}

\author{
Diane M.Makuc, Bengt Haglund, Deborah D. Ingram, Joel C. Kleinman, and \\ Jacob J. Feldman
}

\begin{abstract}
Measurement of the availability of health care providers in a geographic area is a useful component in assessing access to health care. One of the problems associated with the county provider-to-population ratio as a measure of availability is that patients frequently travel outside their counties of residence for health care, especially those residing in nonmetropolitan counties. Thus, in measuring the number of providers per capita, it is important that the geographic unit of analysis be a health service area. We have defined health care service areas for the coterminous United States, based on 1988 Medicare data on travel patterns between counties for routine hospital care. We used hierarchical cluster analysis to group counties into 802 service areas. More than one half of the service areas include only nonmetropolitan counties. The service areas vary substantially in the availability of health care resources as measured by physicians and hospital beds per 100,000 population. For almost all of the service areas, the majority of hospital stays by area residents occur within the service area. In contrast, for 39 percent of counties, the majority of hospital stays by county residents occur outside the county. Thus, the service areas are a more appropriate georgraphic unit than the county for measuring the availability of health care.
\end{abstract}

\section{Background}

Measuring the availability of health care providers is often an important component of research on access to health care. A traditional measure of physician availability is the physician-to-population ratio which is defined as the ratio of the number of physicians in a specified geographic area to the population within that area. The county has frequently been used as the geographic unit of analysis because county data are readily available; however, it is of limited value because many people obtain their medical care from providers outside their counties of residence. The objectives of this paper are: (1) to review some of the limitations of physician-topopulation ratios, particularly regarding the effect of travel between communities for health care, and (2) to describe newly defined national health care service areas that can be used in measuring provider availability.

*For further information, contact: Diane M. Makuc, DrPH, National Center for Health Statistics, 6525 Belcrest Road, Hyattsville, MD 20782. 
Limitations of Physician-to-Population Ratios. A substantial amount of literature discusses the limitations of simple physician-to-population ratios (Department of Health, Education, and Welfare, 1980). Perhaps the most basic point to remember is that the number of providers in an area may be a less important determinant of access to health care than other factors such as socioeconomic status and health insurance coverage (Kleinman \& Wilson, 1977; Makuc, Kleinman, \& Machlin, 1983). This point is illustrated by national data on use of early prenatal care for married women age 20 years and older who are residents of nonmetropolitan counties (Makuc, et al., 1983). After controlling for educational attainment, the percent of black mothers without early prenatal care differed by 5 to 8 percentage points between areas with low and high physician availability in 1980. For white mothers, differences between those living in areas with low and high physician availability were even smaller-only 1 to 2 percentage points. In contrast, after controlling for physician availability, differences in use of early prenatal care by race and education were much greater-about 30 percentage points between whites with some college education and blacks without a high school education. Thus, educational attainment and race were much more strongly associated with use of early prenatal care than physician availability. This finding indicates that merely increasing the number of physicians would do little to increase use of early prenatal care.

Other limitations of physician-to-population ratios relate to specific problems with the ratio itself (DHEW, 1980). First, simply counting the number of physicians does not take into account differences in productivity among physicians due to differences in work hours, use of allied health care providers, or time spent in nonclinical activities. Second, defining the denominator of the physician-to-population ratio as the total population does not take into account differences in health care needs among different subgroups of the population. For example, the greater health care needs of the elderly would not be taken into account by a ratio that assigns equal weight to all individuals in the denominator. Another limitation is that use of an arbitrary geographic unit such as a county does not take into account frequent travel between communities for health care. It is important that the geographic unit of analysis be a health service area based on travel patterns for health care.

Travel for Health Care. An analysis of data from the 1978 National Health Interview Survey (NHIS) showed that a substantial percentage of physician visits occurred outside the patient's county of residence, especially for residents of nonmetropolitan counties (Kleinman \& Makuc, 1983). In analyzing travel patterns for health care, county of patient's residence was categorized into 10 groups based on metropolitan status, adjacency to a metropoltian statistical area (MSA), and population density (Hines, Brown \& Zimmer, 1975). The 10 categories of counties range from those containing the central city of large MSAs to rural counties that are not 
adjacent to an MSA. The percent of physician visits that involved travel across county lines varied from 7 percent among residents of large MSA core counties to almost 50 percent for residents of rural counties (Kleinman \& Makuc, 1983). The proportion of visits that occurred outside the county of residence increased with decreasing population density, both among metropolitan and nonmetropolitan counties. A relatively large percentage of visits by residents of large MSA fringe counties occurred outside the county of residence, reflecting the use of physicians in the central city of the MSA. Among nonmetropolitan counties, visits by persons living in counties adjacent to MSAs were somewhat more likely to involve crossing county lines than those not adjacent to MSAs.

Focusing on physician visits that involved crossing county lines, the type of county where these visits occurred varied according to the type of county of residence (Kleinman \& Makuc, 1983). Not surprisingly, almost all travel by residents of metropolitan counties was to other metropolitan counties. A substantial percent of travel by residents of nonmetropolitan counties adjacent to an MSA was to metropolitan counties, especially to medium and small MSAs. For residents of nonmetropolitan counties not adjacent to an MSA, however, most of the travel was to other nonmetropolitan counties. Among rural residents not adjacent to an MSA, almost 40 percent of visits outside the county of residence occurred in "less urban" nonmetropolitan counties.

The data on travel patterns for physician visits were used to illustrate the impact of travel on county physician-to-population ratios by calculating an "effective" physician supply for each type of county (Kleinman \& Makuc, 1983). An adjusted physician-to-population ratio (Rj) was computed by allocating physicians to each county type in proportion to the use of these physicians by residents as follows:

$R_{i}=\sum P_{i j} * D_{i} / N_{i}$ where

$P_{i j}=$ proportion of visits occurring in counties of type $i$ that are made

by residents of counties of type $j$,

$D_{i}=$ number of physicians in counties of type $i$, and

$\mathrm{N}_{\mathrm{i}}$ = population of county type $\mathrm{j}$.

Among those visits that involve travel across county lines, the tendency is for residents of less populated counties to travel to more populated counties. Thus, this adjustment procedure tends to decrease the "effective" physician supply in the more populated counties and increase "effective" physician supply in less populated counties, thereby decreasing variation in physician supply among different types of counties. For example, variation in physician-to-population ratios among the 10 categories of counties was reduced from more than sixfold to less than threefold by the adjustment procedure (Kleinman \& Makuc, 1983). Unadjusted ratios ranged from 35 per 100,000 in rural counties adjacent to an MSA to 215 per 100,000 in counties containing the central city of a large MSA. In contrast, adjusted ratios ranged from 77 for rural counties to 196 for large MSA core counties. 
Adjustment doubled the physician-to-population ratio for rural counties. These results illustrate that using physician-to-population ratios based on counties can be very misleading, particularly in rural counties, because such ratios do not take into account the substantial amount of travel across county boundaries for care. However, it should be noted that this adjustment did not take into account the longer travel times to physicians for residents of rural counties.

Health Service Areas. Service areas are needed to more accurately measure per capita health care resources. A number of approaches have been used to define health care service areas (Shannon \& Pyle, 1989; Garnick, Luft, Robinson, \& Tetreault, 1987; Makuc, Kleinman, \& Pierre, 1985). Most studies that have defined or used health care service areas focus on a single state or local area.

One of the few attempts to identify service areas for the entire United States was health care commuting areas (HCCAs), defined by grouping counties based on 1968 national natality data, 1969 national mortality data, and 1970 census data on commuting for work (Transaction Systems, 1976). The natality data file contains data on county of mother's residence and county of delivery, providing information on travel patterns for obstetrical care. Similarly, the mortality data file includes the county of residence of the decedent as well as the county of death, providing information on travel patterns for hospital stays of decedents who die in hospitals. An algorithm was developed that grouped counties into 780 areas so that travel outside areas at birth and death and for employment was minimized (Transactions Systems, 1976). Data from the 1978 National Health Interview Survey were used to compare how well the HCCAs and two other types of county aggregations performed as health service areas (Makuc, et al.,1985). The 780 HCCAs were compared with 183 areas developed for economic analyses by the Bureau of Economic Analysis and 492 basic trading areas developed by Rand McNally. The results of this analysis indicated that the HCCAs performed better as health service areas than the two other types of areas because they are the smallest in size and population and yet exhibit an amount of outside-area travel for care similar to that of the two larger types of areas (Makuc, et al., 1985). This analysis also demonstrated that travel outside HCCAs for physician visits was substantially less than outside counties, particularly for nonmetropolitan residents. For residents of nonmetropolitan counties 25 percent of physician visits occurred outside the county of residence compared with only 11 percent of the visits outside the HCCA of residence. For residents of rural counties, 45 percent of physician visits occurred outside the county of residence compared with 16 percent outside the HCCA of residence. The percent of hospital stays outside HCCAs was also substantially less than for counties $(13 \%$ versus $30 \%$ overall). For rural residents, 70 percent of hospital stays involved travel across county lines in comparison with 31 percent across HCCA lines. 
Although the HCCAs appeared to perform reasonably well as service areas, they are based on data that are 20 years old.

\section{Methods}

A project at the National Center for Health Statistics was recently conducted to define national health service areas. We have defined a health service area as one or more counties that are relatively self-contained with respect to the provision of routine hospital care. Every county in the coterminous United States is assigned to a single service area.

Data Source. County was selected as the basic geographic unit of analysis because it was the smallest unit for which most national data sources are currently available. Three sources with county-level data for the entire United States were considered-natality, mortality, and Medicare. We selected 1988 Medicare data on short-stay hospital stays as the most appropriate data source because it provides information on all types of hospital stays and includes information about type of stay, so that stays for specialized care could be eliminated. The drawback of Medicare data is that this information is only available for persons age 65 years and older (about $17 \%$ of hospital discharges in 1988). However, national data from the 1978 and 1989 NHIS indicate that travel patterns for ambulatory medical care and for hospital care do not differ substantially by age (Kleinman \& Makuc, 1983; Makuc, Haglund, Ingram, Kleinman, \& Feldman, in press).

Cluster Analysis. Hierarchical cluster analysis with the average linkage method was used to group counties into service areas (Hartigan, 1975; SAS Institute, 1985). The data input to the cluster analysis was a matrix of distances between pairs of counties. The distances measure the strength of the flow between pairs of counties for routine hospital care. It should be noted that distance in this context has nothing to do with physical distance. The distances between pairs of counties are a function of the total flow of hospital stays between two counties and the consumption of stays in the smaller county. The flow between counties is divided by consumption of hospital stays in the smaller county so that large counties do not dominate the analysis. A similar analytic approach was used by the Department of Agriculture to define labor market areas based on employment commuting patterns (Tolbert \& Killian, 1987).

In carrying out a cluster analysis, a decision must be made concerning the appropriate number of clusters. In making this decision we considered previous research on national health service areas. An evaluation of the previously defined HCCAs indicated that these areas performed well as health service areas (Makuc, et al., 1985). We decided to develop a solution with about 800 clusters, approximately the same number as HCCAs, under 
the assumption that the total number of service areas has not changed substantially between 1970 and 1988 .

After the cluster analysis was completed, the health service areas were sent to each state for review. This provided a check on the validity of our methods across the United States. Overall, the health service areas produced by the cluster analysis were consistent with the knowledge of state experts regarding travel patterns in their states. Suggested changes were made to the health service areas for 27 counties in nine states. Further details of the methods used to define the service areas and information about alternative solutions considered are available elsewhere (Makuc, Haglund, Ingram, Kleinman \& Feldman, 1991; Makuc, et al., in press).

\section{Results}

There were 802 areas in the final solution. Tables 1 and 2 compare the characteristics of service areas that include a metropolitan county with those that include only nonmetropolitan counties. Of the 802 service areas, $436(54 \%)$ contain only nonmetropolitan counties. Among the nonmetropolitan service areas, 16 percent include only one county, 74 percent include two to five counties, and 10 percent include six or more counties (Table 1). In contrast, 6 percent of the metropolitan service areas include a single county, 66 percent include two to five counties, and 29 percent include six or more counties.

The median population is 55,000 for the nonmetropolitan service areas; 10 percent of the nonmetropolitan areas have a population of 15,000 or fewer; and 10 percent have a population of 144,000 or more. The median number of patient care physicians per 100,000 population is 84 for the nonmetropolitan service areas and 132 for the metropolitan service areas. Among the nonmetropolitan service areas, 10 percent have 50 or fewer physicians per 100,000 population and 10 percent have 126 or more physicians per 100,000 population.

Federally designated primary care health manpower shortage areas as of 1987 are found in the vast majority of the service areas, 75 percent of the nonmetropolitan service areas, and 89 percent of the metropolitan service areas (Health Resources and Services Administration, 1989). This is consistent with the algorithm used to form the service areas in that counties that do not have health care facilities must link with those that do. If only whole county shortage areas are considered, then 46 percent of the nonmetropolitan service areas and 43 percent of the metropolitan service areas include whole county shortage areas.

In contrast to physician supply, the nonmetropolitan service areas have a higher median number of short-stay general hospital beds per 100,000 population than the metropolitan service areas (462 versus 393) (Table 1). Among the nonmetropolitan areas, 10 percent have 286 or fewer beds per 


\section{Table 1. Selected Characteristics of Health Service Areas by Metropolitan Status of Areas.}

\begin{tabular}{|c|c|c|c|}
\hline & Total & Metro & Nonmetro \\
\hline Number of areas & 802 & 366 & 436 \\
\hline Counties per area & \multicolumn{3}{|c|}{ Percent distribution } \\
\hline 1 & 11 & 6 & 16 \\
\hline $2-3$ & 42 & 33 & 49 \\
\hline $4-5$ & 29 & 33 & 25 \\
\hline $6-9$ & 16 & 24 & 10 \\
\hline 10 or more & 2 & 5 & 0 \\
\hline Population, 1987 & \multicolumn{3}{|c|}{ Population in thousands } \\
\hline 10th percentile & 23 & 135 & 15 \\
\hline 50th percentile & 123 & 293 & 55 \\
\hline 90th percentile & 613 & 1,308 & 144 \\
\hline Patient care physicians, 1986 & \multicolumn{3}{|c|}{ Physicians per 100,000 population } \\
\hline 10th percentile & 59 & 83 & 50 \\
\hline 50th percentile & 100 & 132 & 84 \\
\hline 90th percentile & 198 & 232 & 126 \\
\hline Short-stay hospital beds, 1987 & \multicolumn{3}{|c|}{ Beds per 100,000 population } \\
\hline 10th percentile & 272 & 253 & 286 \\
\hline 50th percentile & 429 & 393 & 462 \\
\hline 90th percentile & 708 & 618 & 783 \\
\hline Selected hospital services, 1987 & \multicolumn{3}{|c|}{ Percent of areas } \\
\hline CAT scanner & 86 & 100 & 75 \\
\hline Cardiac catheterization & 44 & 80 & 14 \\
\hline NMR & 26 & 48 & 7 \\
\hline
\end{tabular}

Note: Metropolitan service areas include at least one metropolitan county.

Source: Analysis of data from Health Resources and Services Administration, Area Resource File, 1989.

100,000 population and 10 percent have 783 or more beds per 100,000 population. State data on community hospital beds are consistent with these results in showing that the states with the greatest supply of hospital beds in relation to population tend to be primarily nonmetropolitan. The highest ratios of hospital beds to population are found in North Dakota, South Dakota, Nebraska, Montana, and Mississippi, with 1988 community 
Table 2. Travel Outside Health Service Areas and Counties for Routine Hospital Stays by Medicare Beneficiaries, According to Metropolitan Status, 1988.

\begin{tabular}{|c|c|c|c|c|c|c|}
\hline & \multicolumn{3}{|c|}{ Health Service Areas } & \multicolumn{3}{|c|}{ Counties } \\
\hline & All & Metro & Nonmetro & All & Metro & Nonmetro \\
\hline Stays outside area $b$ & \multicolumn{6}{|c|}{ Percent distribution of areas } \\
\hline Less than $25 \%$ & 66 & 90 & 45 & 23 & 49 & 14 \\
\hline $25-49 \%$ & 34 & 10 & 54 & 38 & 30 & 40 \\
\hline \multirow[t]{2}{*}{$50 \%$ or greater } & 0 & 0 & 1 & 39 & 20 & 45 \\
\hline & \multicolumn{6}{|c|}{ Percent distribution of population } \\
\hline Less than $25 \%$ & 93 & 97 & 66 & 65 & 75 & 31 \\
\hline $25-49 \%$ & 7 & 3 & 34 & 24 & 18 & 43 \\
\hline $50 \%$ or more & 0 & 0 & 0 & 11 & 6 & 27 \\
\hline
\end{tabular}

Note: Metropolitan service areas include at least one metropolitan county.

hospital bed-to-population ratios more than 30 percent greater than the national average (NCHS, 1991).

There are very striking differences between the metropolitan and nonmetropolitan service areas with respect to the availability of selected specialized services (Table 1). The most specialized service, nuclear magnetic resonance, is available in only 7 percent of nonmetropolitan areas compared with 48 percent of metropolitan areas. Only 14 percent of nonmetropolitan service areas have a hospital that provides cardiac catheterization, whereas 80 percent of metropolitan areas have such services available. In contrast, CAT scans are available in 75 percent of the nonmetropolitan areas and all of the metropolitan areas.

In Table 2 service areas and counties have been categorized according to the percent of routine hospital stays outside the area by Medicare beneficiaries who are area residents. The categories correspond to good (less than $25 \%$ ), fair ( $25 \%$ to $49 \%$ ), and poor ( $50 \%$ or more) degrees of self-containment for routine hospital stays. The results show that 66 percent of service areas had fewer than one quarter of the residents' stays occurring outside the service area, and less than 1 percent of the service areas had the majority of stays outside the area of residence. In contrast, only 23 percent of counties had fewer than one quarter of residents' stays occurring outside the county and 39 percent of counties had more than one half of the residents' stays occurring outside the county. Virtually all of the nonmetropolitan service areas have fair or good degrees of self-containment, whereas only 54 
percent of nonmetropolitan counties meet this criterion. The more populated nonmetropolitan service areas and counties have less travel outside the area of residence than those with less population. For example, the 45 percent of nonmetropolitan service areas that have good self-containment account for 66 percent of the population residing in nonmetropolitan areas. The results in Table 2 indicate that in comparison to a county, the population within a service area is much more likely to use the health resources within the service area.

\section{Summary}

The number of health care providers in a geographic area may be a less important determinant of access to health care than other factors such as the patient's socioeconomic status and health insurance coverage. Nevertheless, measurement of the number of physicians per capita is a useful component in assessing access to health care. One of the problems associated with the county physician-to-population ratio as a measure of physician availability is that a substantial percentage of physician visits occur outside the patient's county of residence, especially for residents of nonmetropolitan counties. In measuring the number of physicians per capita, it is important that the geographic unit of analysis be a health service area.

There have been few efforts to define health care service areas for the entire United States. One such effort was HCCAs, which are based on data that are now 20 years old. We have defined new health care service areas for the coterminous United States, based on 1988 Medicare data on travel patterns between counties for routine hospital care. We used hierarchical cluster analysis and the average linkage method to group counties into 802 service areas.

More than one half of the service areas include only nonmetropolitan counties. Both metropolitan and nonmetropolitan service areas exhibit substantial variability in the availability of health care resources as measured by physicians and hospital beds per 100,000 population. Further, for almost all of the service areas, the majority of hospital stays by area residents occur within the service area. In contrast, for 39 percent of counties, the majority of hospital stays by county residents occur outside the county. Thus, the service areas are much more self-contained than counties with respect to the provision of routine hospital care, thereby providing a more appropriate geographic unit for measuring the availability of health care than the county.

Further evaluation of the service area definitions will use 1989 data from the National Health Interview Survey to examine travel outside the new service areas for ambulatory medical care. We also plan to use the service area definitions to study geographic variation in physician availability and 
to further investigate the relationship between physician availability and use of physician services.

\section{REFERENCES}

Department of Health, Education, and Welfare. (1980). Evaluation of health manpower shortage area criteria (DHEW Publication No. HRA 80-20). Washington, DC: Health Resources and Services Administration.

Garnick D.W., Luft H.S., Robinson J.C., \& Tetreault J. (1987). A ppropriate measures of hospital market areas. Health Services Research, 22(1), 69-89.

Hartigan J.A. (1975). Clustering algorithms. New York, NY: John Wiley and Sons.

Health Resources and Services Administration. (1989). Area resource file. Washington, DC: Author.

Hines F.K., Brown D.L., \& Zimmer J.M. (1975). Social and economic characteristics of the population in metropolitan and nonmetropolitan counties, 1970. Washington, DC: Department of Agriculture.

Kleinman J.C., \& Makuc D.M. (1983). Travel for ambulatory medical care. Medical Care, 21, 543557.

Kleinman J.C., \& Wilson R.W. (1977). Are "medically underserved areas" medically underserved? Health Services Research, 12(2), 147-162.

Makuc D.M., Haglund B., Ingram D.D., Kleinman J.C., \& Feldman J.J. (1991). Use of cluster analysis to identify health care service areas. Proceedings of the 1990 American Statistical Association Social Statistics Section, 260-265.

Makuc D.M., Haglund B., Ingram D.D., Kleinman J.C., \& Feldman J.J. (in press). Health service areas for the United States. National Center for Health Statistics Vital and Health Statistics, 2(112).

Makuc D.M., Kleinman J.C., \& Machlin S.R. (1983). Effects of physician supply on use of physician services. Proceedings of the American Statistical Association Social Statistics Section, 299-303.

Makuc D.M., Kleinman J.C., \& Pierre M.B. (1985). Service areas for ambulatory medical care. Health Services Research, 20(1), 1-18.

National Center for Health Statistics. (1991). Health, United States, 1990. Hyattsville, MD: Public Health Service.

SAS Institute, Inc. (1985). SAS user's guide: Statistics, version 5 edition. Cary, NC: SAS Institute, Inc.

Shannon G.W., \& Pyle G.F. (1989). The definition and measurement of hospital market areas. Unpublished manuscript.

Tolbert C.M., \& Killian M.S. (1987). Labor market areas for the United States (USDA Staff Report No. AGES870721). Washington, DC: Department of Agriculture.

Transactions Systems, Inc. (1976). Evaluation of alternative health area definition methods. (DHEW Contract No. HRA 230-75-0080). Washington, DC: Health Resources and Services Administration. 